aged 5 to $11 .{ }^{6}$ Lichen sclerosus et atrophicus also affects adult men on the penis (usually the glans, prepuce, or both') or elsewhere, and in older men it is the commonest cause of balanitis xerotica obliterans, a possibly premalignant condition. The clinical course of lichen sclerosus et atrophicus in relation to the three age groups is obscure. In adults circumcision is usually beneficial for lichen sclerosus et atrophicus of the glans and of the prepuce, and a strong corticosteroid is also helpful.

In young girls lichen sclerosus et atrophicus probably affects the anogenital area most commonly but certainly not exclusively. The strikingly pale, atrophic, and speckled lesions may be symptomless, but they may itch, perhaps become infected with staphylococci or streptococci, and even lead to intractable constipation because of discomfort on defecation. The condition, especially if coupled with the purpura, haemorrhagic blisters, and frank bleeding induced by scratching or washing, may lead to false suspicions of sexual abuse.$^{89}$ Lichen sclerosus et atrophicus is managed in these patients with bland emollients, good hygiene, and sometimes a mild corticosteroid. Lesions improve at puberty but probably do not remit completely.

Lichen sclerosus et atrophicus may present at any age in adult women and commonly affects the anogenital area, causing itching or soreness. The possibility of associated autoimmune disease should be explored. Management is similar to that in children, although strong corticosteroids are justifiable for short periods. Testosterone ointment is thought beneficial by some but is not widely used in Britain. The condition never affects the vagina, but dyspareunia may be caused by introital stenosis. Pregnancy and delivery are uninfluenced by lichen sclerosus et atrophicus. Patients can be helped by being given a leaflet on the condition; and they should be told that an operation is indicated only to obtain biopsy specimens, for rare cases where adhesions may form, sometimes for introital stenosis, and for malignancy.

The risk of malignancy (squamous cell carcinoma) is raised, about $6 \%,{ }^{210}$ and continuing supervision thus seems indicated. The factors that cause malignancy are unknown, but human papillomavirus may be important. The dermatologist, gynaecologist, and pathologist need to work closely together to manage patients with lichen sclerosus et atrophicus: if the condition passes unappreciated in a gynaecological clinic unjustifiable fears of malignancy may lead to an unnecessary operation. The problem has been compounded in the past by confused terminology. ${ }^{11}$ The International Society for the Study of Vulvar Disease and the International Society of Gynecological Pathologists have clarified the terminology of malignant vulval lesions, ${ }^{12}$ and at its congress in 1987 the former ratified a new and more satisfactory terminology for non-malignant epithelial conditions, which is likely to be adopted also by the gynaecological pathologists. When lichen sclerosus et atrophicus is clearly described in histological terms, with the presence or absence of changes in response to rubbing, human papillomavirus infection, and malignancy noted, we shall have a sound base from which to explore other facets of this disease.

C M RIDLEY

Consultant Dermatologist,

Elizabeth Garrett Anderson and Whittington Hospitals,

London NW1 2AP

1 Harrington CI, Dunsmore IR. An investigation into the incidence of autoimmune disorders in patients with lichen sclerosus et atrophicus. Br $\mathcal{Y}$ Dermatol 1981;104:563-6.

2 Meyrick Thomas RH, Ridley CM, McGibbon DH, Black MM. Lichen sclerosus et atrophicus and autoimmunity in 350 women. $B r \mathcal{F}$ Dermatol (in press).
3 Meyrick Thomas RH, Ridley CM, Black MM. The association of lichen sclerosus et atrophicus to autoimmune related disease in males. $\mathrm{Br} \mathcal{F}$ Dermatol 1983;109:661-4.

Meyrick Thomas RH, Ridley CM, Black MM. The association of lichen sclerosus et atrophicus and autoimmune related diseases in males: an addendum. Br 7 Dermatol 1984;111:371.

Meyrick Thomas RH, Kennedy CTC. The development of lichen sclerosus et atrophicus in monozygotic twin girls. Br J Dermatol 1986;114:377-9.

6 Chalmers RTG, Burton PA, Bennett RF, Goring CC, Smith PJB. Lichen sclerosus et atrophicus: Chalmers RTG, Burton PA, Bennett RF, Goring CC, Smith PJB. Lichen sclerosus et at

7 Meyrick Thomas RH, Ridley CM, Black MM. Clinical features and therapy of lichen sclerosus et atrophicus affecting males. Clin Exp Dermatol 1987;12:126-8.

8 Handfield-Jones SE, Hinde FRJ, Kennedy CTC. Lichen sclerosus in children misdiagnosed as sexual abuse. Br Med f 1987;294:1404-5.

9 Priestley BL, Bleehen SS. Lichen sclerosus et atrophicus in children misdiagnosed as sexual abuse. Br Med f 1987;295;211.

10 Wallace HJ. Lichen sclerosus et atrophicus. Transactions of the St fohn's Hospital Dermatological Sociery 1971:57:9-30.

11 Ridley CM. Recent advances in vulval diseases. In: Champion RH, ed. Recent advances in dermatology. London: Churchill Livingstone, 1986:127.

12 Ridley CM. Nomenclature of non-neoplastic vulval conditions. Brf Dermatol 1986;115:647-8.

\section{Saving skin}

How many diagnoses do doctors miss simply by not thinking of them? Occupational dermatitis is the commonest occupational disease, with half of all the diseases prescribed for industrial injury benefit in 1982-3 being "non-infective dermatitis of external origin." Yet it is only too easy to see patients with dermatitis of the hands more in terms of medicaments than of investigation, diagnosis, and preven- $N$ tion. The Health and Safety Executive has just launched a $Z$ year's campaign to heighten awareness of occupational dermatitis. Its Employment Medical Advisory Service is $\underset{3}{3}$ taking the campaign directly to both the workforce and management as well as publicising it to doctors, nurses, occupational hygienists, and other specialists.

Occupational dermatitis may usefully be defined as dermatitis that would not have occurred had the patient not been carrying out his or her work. It is a contact dermatitis, the result of the skin's reaction to irritants or allergens-irritants that attack directly (such as alkalis) and allergens that attack through a delayed cell mediated allergic mechanism (such as chromate). Not all occupational skin disease is contact dermatitis-the term includes skin diseases as diverse as urticaria and carcinoma - but the great majority is.

The true prevalence of occupational dermatitis is not known for any part of the world. Many cases escape being included in any statistical report because the patient goes on working and does not claim any compensation. Most figures quoted are therefore underestimates. Some inkling of how large the true figure might be, however, is provided by the results of a population study in the United States. ${ }^{2}$ Nearly a third of a 20000 sample of the general population were found $\widetilde{N}$ to have "some skin pathology that should be evaluated by a $\frac{?}{0}$ physician" and of this group nearly a quarter had occupational exposure to agents that were potentially toxic to the $N$ skin. Prevalence figures are always difficult to assess, if only $\underset{\omega}{\mathcal{N}}$ because some cases are entirely occupational while others 2 result from a combination of occupational and constitutional $\stackrel{\varrho}{\llcorner}$ factors, such as shampooing and atopic eczema. Nevertheless, the impact of occupational dermatoses on the personal, social, and economic life of patients tends to be underestimated by others, sometimes even by doctors. The effect $\stackrel{\mathbb{D}}{\mathbb{D}}$ of chronic chromate dermatitis, for example, may be com- $\stackrel{\mathbb{\Omega}}{\Omega}$ parable with that of the amputation of a limb, a comparison aptly crystallised in the phrase "chromate cripple."

Scarcely any substance is entirely harmless to the skin if direct contact is heavy or prolonged enough, and even office 흘 
workers may develop occupational dermatoses. ${ }^{3}$ Most occupational contact irritants are alkalis, acids, soaps, detergents, organic solvents, reducing agents, oxidising agents, and physical factors such as friction; the common occupational contact allergens are chromate, synthetic adhesives and sealants, biocides, and a wide variety of low $(<1000)$ molecular weight organic chemicals. Such substances are met with as much in hairdressing and catering as in engineering and construction.

Occupational dermatitis is sometimes difficult to diagnose as accurately as its effective prevention demands, especially when allergens may be responsible. But much occupational dermatitis is due to irritants rather than to allergens and is preventable if we use the knowledge we already have. Quick, simple, and inexpensive preventive measures are still being needlessly ignored. This is the core message of the Health and Safety Executive campaign. Once well established, the prognosis of occupational dermatitis is surprisingly poor, ${ }^{4}$ and hence primary prevention is paramount. Individuals and companies who believe themselves free of skin problems may be storing them up for the future by their current work practices. The time to think about skin hazards is while they are still potential hazards and not to delay matters until dermatitis has already developed.

Information on many aspects of preventing occupational dermatitis is available by contacting local Employment Medical Advisory Services offices (listed under Health and Safety Executive in the telephone book) or from the Dermatitis Campaign Secretariat, Health and Safety Executive, Magdalen House, Trinity Road, Bootle L20 3QZ (051 951 9545). The National Eczema Society also provides useful information about eczema at work (Tavistock House North, Tavistock Square, London WC1H 9SR (01 388 4097)). Doctors and others may find themselves being asked for help in the campaign by giving or attending a lecture or seminar. The "Save Your Skin" campaign is worthy of their support. Meanwhile we could all do more to find out precisely what does get on to our patients' skins at work.

R J G RYCROFT

Consultant Dermatologist,

St John's Hospital for Diseases of the Skin,

London WC2H 7B

and

Senior Employment Medical Adviser (Dermatology),

Health and Safety Executive,

London W2 4TF

1 Department of Health and Social Security. Social security statistics. London: HMSO, 1985.

2 Johnson ML, Roberts J. Prevalence of dermatological disease in the United States: a review of the National Health and Nutrition Examination Survey, 1971-1974. Am f Ind Med 1985;8:451-60. 3 Rycroft RJG. Occupational diseases among office personnel. State of the Art Reviews in Occupational Medicine 1986;1:323-8.

4 Fregert S. Occupational dermatitis in a 10-year material. Contact Dermatitis 1975;1:96-107.

\section{Patient safety and doctors with HIV infection}

After the recent case in which the High Court stopped the News of the World naming two doctors with the acquired immune deficiency syndrome (AIDS) the media justifiably concentrated on the risk to patients being cared for by doctors infected with the human immunodeficiency virus (HIV) (p 1339). Less justifiable was the suggestion that some doctors, and in particular the Department of Health, are engaged in a cover up to protect doctors.

Once again it is important to restate that HIV infection and AIDS are not contagious. There is no well documented evidence that the virus is spread by saliva or sputum, casual or social contact, and by sharing cups, eating and cooking utensils, toilets, and air space with an infected person. This is supported both by the facts that non-sexual family contacts of patients with the AIDS related complex or AIDS have not been infected with HIV and that health care workers in the United States caring for many people infected with HIV have not been infected casually. The only recorded cases of infection have followed needlestick injuries or mucous membrane exposure, but only $1 \%$ have seroconverted after such exposure. This illustrates that apart from sexual transmission infection has been shown to occur only if blood is deposited beneath the skin or on to mucous membranes. There are no clinical or epidemiological data to suggest that any doctors or dentists have infected one of their patients. The suggestion that this could occur is purely theoretical.

Nevertheless, this lack of evidence should not allow us to be cavalier in our approach to the possible threat of infection to patients, but our approach must be based on a rational and non-emotional assessment of risk. The risk to a patient of infection by an infected doctor must depend on what procedures are carried out by that doctor. Thus there is a theoretical risk of transmission of HIV if an infected doctor is carrying out an invasive or operative procedure and himself bleeds into his patient. The guidelines outlined by the United States Centers for Disease Control in August 1987 state: "The question of whether workers infected with HIVespecially those who perform invasive procedures-can adequately and safely be allowed to perform patient-care duties or whether their work assignments should be changed must be determined on an individual basis." The BMA has said that those carrying out invasive procedures should not continue to work where they could theoretically infect a patient. Many doctors and patients might think that given the knowledge that blood is infectious and that surgeons with hepatitis B (even though more infectious) have infected patients it would be preferable for the surgeon to cease operating. Here a lack of evidence for such events having occurred may not be sufficiently strong grounds to avoid the pragmatic decision to stop operating. Others, however, would argue that adherence to good control of infection procedures such as wearing gloves and being cautious when using sharp instruments and needles would mean that infection should not occur.

Leaving aside the theoretical possibilities of invasive procedures, sensible control of infection procedures used by doctors at large would protect all patients. Thus, gloves should be worn for any procedures that necessitate contact with the patient's body fluids. Also an infected practitioner with hand lesions such as eczema or open wounds should cover these; these procedures should be second nature to doctors. It has been suggested that the dementia associated with AIDS would put patients at risk. Again, we have 